\title{
Optimization of Columns and Bent Caps of RC Bridges for Cost and $\mathrm{CO}_{2}$ Emission
}

\author{
Ali Kaveh", Lida Mottaghi², Ramezan Ali Izadifard² \\ ${ }^{1}$ School of Civil Engineering, Iran University of Science and Technology, 16846-13114 Tehran, Iran \\ 2 Civil Engineering Department, Imam Khomeini International University, 34148-96818 Qazvin, Iran \\ * Corresponding author, e-mail: alikaveh@iust.ac.ir
}

Received: 17 October 2021, Accepted: 16 February 2022, Published online: 22 February 2022

\begin{abstract}
This paper describes a methodology for optimal seismic design of reinforced concrete 3D columns and bent caps (beams) of bridges. Design variables include compressive strength of concrete, geometry, as well as longitudinal and shear reinforcement of columns and beams. The optimization is performed to minimize the cost and $\mathrm{CO}_{2}$ emissions using the enhanced colliding bodies optimization (ECBO) algorithm. The trade-off between cost and $\mathrm{CO}_{2}$ emissions shows that in the design for minimizing $\mathrm{CO}_{2}$ emissions compared to the design based on the cost minimization, increasing $1.4 \%$ in cost can decrease $\mathrm{CO}_{2}$ emissions by $6.1 \%$.
\end{abstract}

Keywords

optimal cost, optimal $\mathrm{CO}_{2}$ emissions, RC bridge, columns, bent caps, ECBO algorithm

\section{Introduction}

Engineers attempt to design structures which are economical and sufficiently resistant to natural hazards, while the final design obtained by the trial-and-error approach is not sufficient to meet economic and safety criteria simultaneously. Therefore, recently, studies have been conducted on the optimal design of bridges with the objective of minimizing the cost. Martí et al. [1] optimally designed the prestressed concrete precast road bridges with double U-shaped cross-section. They employed hybrid simulated annealing algorithm to minimize the cost. Srinivas and Ramanjaneyulu [2] optimized the cost of T-girder bridge deck by using genetic algorithms (GA) and artificial neural networks. Kaveh et al. [3] utilized three metaheuristics algorithm including Colliding Bodies Optimization (CBO), Modified Colliding Bodies Optimization (MCBO), and Particle Swarm Optimization (PSO) to optimize the cost of post-tensioned concrete box girder of single span bridges. Pedro et al. [4] used a two-stage optimization approach to minimize the material costs of the steel-concrete composite I-girder bridges. Yepes et al. [5] optimally designed the post-tensioned concrete box-girder pedestrian deck to minimize the economic cost. Penadés-Plà et al. [6] employed a robust design optimization method to design a continuous prestressed concrete box girder pedestrian bridge.
On the other hand, reduction of Greenhouse Gases (GHGs) is a major global challenge. Construction industry has a remarkable contribution on GHG, and carbon dioxide $\left(\mathrm{CO}_{2}\right)$ is a major part of it. Studies have employed the strategies to reduce the $\mathrm{CO}_{2}$ emissions from the reinforced concrete (RC) structure, one of which is the use of optimization techniques during the design phase of RC frames [7-12]. Studies have been conducted to reduce $\mathrm{CO}_{2}$ emissions on bridges. Yepes et al. [13] developed a method to optimally design the precast-prestressed bridges with a double U-shape cross-section, where the objective functions minimized the cost and $\mathrm{CO}_{2}$ emissions. GarcíaSegura et al. [14] minimized the cost and $\mathrm{CO}_{2}$ emission of the post-tensioned concrete box-girder pedestrian bridges with hybrid harmony search algorithms. GarcíaSegura and Yepes [15] employed a multi-objective harmony search algorithm to reduce $\mathrm{CO}_{2}$ emissions, cost, and overall safety factor of post-tensioned concrete road bridges. In the reviewed studies, the optimal design of the superstructures of bridge was considered. Meanwhile, the piers made up $20-50 \%$ of the total cost of the bridges [16]. Martínez et al. [16] developed a methodology to optimize the cost of RC bridge piers with hollow rectangular sections and constant cross-sections. In their process, they 
used the ant colony optimization algorithm (ACO), GA, and threshold acceptance algorithm. In another study, Martínez et al. [17] employed the ACO algorithm to optimally design RC tall bridge piers with hollow rectangular sections, in which the dimensions of the piers varied along their length. Fazli and Pakbaz [18] presented the optimization framework for performance-based seismic design of bridges consisting of multi-column RC pier substructures.

A review of the literature showed that no study has been conducted on the optimal design of RC columns and bent caps (beams) of bridge with the objective of minimizing $\mathrm{CO}_{2}$ emissions. Therefore, the aim of this study is to present a methodology for the optimal design of 3D columns and bent caps of bridges with the objective of minimizing cost and $\mathrm{CO}_{2}$ emissions and investigating the tradeoff between optimal cost and optimal $\mathrm{CO}_{2}$ emission for them.

After this introduction, a brief explanation of the algorithm used in this paper is presented in Section 2. The formulation of optimal design is presented in Section 3. Numerical example and the results are studied in Section 4. Finally, conclusions are presented in Section 5.

\section{Optimization algorithm}

In this study, an advanced version of the $\mathrm{CBO}$ [19] known as the ECBO algorithm [20] is used to optimize the problem. In the previous studies the authors $[9,11,21]$ have compared the performance of the algorithms such as VPS, $\mathrm{PSO}, \mathrm{CBO}$ and $\mathrm{ECBO}$, concluding that ECBO has better performance for the present problem, and therefore in this study ECBO is employed as the optimization tool. This algorithm is also presented and discussed in the comprehensive book on many metaheuristic algorithms [22]. The CBO and ECBO algorithms are based on the physical laws governing the collision between objects, where the momentum before the collision is equal to the sum of the momentum after the collision. In order to escape from local optima and increase the convergence speed of the CBO algorithm, the ECBO algorithm uses memory to save a number of historically best Colliding Bodies (CBs) and also utilizes the Pro parameters. Using Pro parameter, one component of the $i$ th $\mathrm{CB}$ will be regenerated randomly in each iteration.

For completeness the procedure of this algorithm is described in the following and its pseudo code is provided in Algorithm 1 [23].

Step 1: The initial position of each collision bodies is determined randomly in the research space according to the following equation:

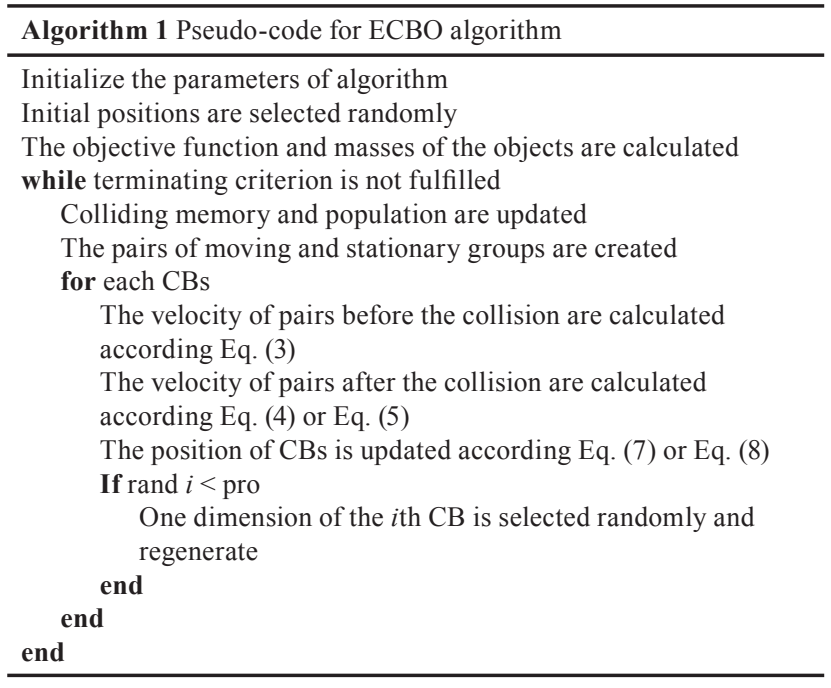

$\boldsymbol{x}_{i}^{0}=\boldsymbol{x}_{\min }+\operatorname{rand}\left(\boldsymbol{x}_{\max }-\boldsymbol{x}_{\min }\right), i=1,2, \ldots, n$,

where $\boldsymbol{x}_{i}^{0}$ is the initial position of the $i$ th $C B, \boldsymbol{x}_{\min }$ and $\boldsymbol{x}_{\max }$, respectively is the minimum and maximum values of the variables, and rand is a random value in the range $[0,1]$ and $n$ is the number of CBs.

Step 2: The mass of each $C B$ is calculated as:

$m_{i}=\frac{\frac{1}{f i t(i)}}{\sum_{j=1}^{n} \frac{1}{f i t(j)}}, i=1,2, \ldots, n$,

Where $f i t(i)$ is the value of the objective function for $C B s$ and $n$ is the population size.

Step 3: In order to save a number of historically best $C B$ vectors and their related mass and objective function values, a Colliding Memory $(C M)$ is utilized. The solution vectors that are saved in $C M$ are added to the population and the same number of current worst $C B S$ are deleted. Finally, $C B S$ are sorted according to their mass in a decreasing order.

Step 4: CBs are divided into two equal groups so-called (i) stationary and (ii) moving objects. Moving objects collide with stationary objects to improve their positions and push stationary objects toward better positions.

Step 5: Before collision, the velocity of moving objects is calculated as:

$v_{i}=x_{i-\frac{n}{2}}-x_{i}, \quad i=\frac{n}{2}+1, \ldots, n$,

Step 6: The velocity of the CBs after the collision in each group is obtained as follows:

Stationary objects: 
$v_{i}^{\prime}=\frac{\left(m_{i+\frac{n}{2}}+\varepsilon m_{i+\frac{n}{2}}\right) v_{i+\frac{n}{2}}}{m_{i}+m_{i+\frac{n}{2}}}, i=1,2, \ldots, \frac{n}{2}$

Moving objects:

$$
v_{i}^{\prime}=\frac{\left(m_{i}-\varepsilon m_{i-\frac{n}{2}}\right) v_{i}}{m_{i}+m_{i-\frac{n}{2}}}, i=\frac{n}{2}+1, \ldots, n
$$

The coefficient of restitution $(\varepsilon)$ is defined as:

$$
\varepsilon=1-\frac{\text { iter }}{\text { iter } \max } \text {. }
$$

Step 7: The new positions of the objects by using the generated velocities after the collision and their old position are updated as follows:

a) The new position of moving object:

$$
x_{i}^{\text {new }}=x_{i-\frac{n}{2}}+\operatorname{rand}^{\circ} v_{i}^{\prime}, \quad i=\frac{n}{2}+1, \frac{n}{2}+2, \ldots, n .
$$

In which $x_{i}^{\text {new }}$ is the new position of the $i$ th $C B s, x_{i-\frac{n}{2}}$ is old position of $i$ th stationary $C B$ and rand is a random vector uniformly distribution in the range $(-1,1) . v_{i}^{\prime}$ is the velocity of $i$ th moving $C B$ after collision. The sign "o" denotes an element-by-element multiplication.

b) The new position of stationary object:

$$
x_{i}^{\text {new }}=x_{i-\frac{n}{2}}+\operatorname{rand}^{\circ} v_{i}^{\prime}, \quad i=\frac{n}{2}+1, \frac{n}{2}+2, \ldots, n,
$$

Where $x_{i}^{\text {new }}$ is the new position of the $i$ th $C B s, x_{i-\frac{n}{2}}$ is old position of $i$ th stationary $C B$ and $v_{i}{ }^{\prime}$ is the velocity after the collision of the $i$ th stationary $C B$.

Step 8: The Pro parameter is compared with the random number $r n_{i}(i=1,2, \ldots, n)$. If Pro $>r n_{i}$, a $C B$ is selected from both moving and stationary groups, and a component of it is randomly regenerated.

Step 9: The process of optimization repeated from Step 2, until terminating criterion is satisfied.

\section{Formulation of design}

\subsection{Loading}

The loading of bridge includes dead loads, live loads, and earthquake loads. The bridge is analyzed under response spectrum analysis (RSA). Dead loads include the weight of girders and slabs as well as weight of the asphalt. The weight per unit volume of concrete is $2.5 \mathrm{ton} / \mathrm{m}^{3}$ and the weight per unit volume of asphalt is $2.2 \mathrm{ton} / \mathrm{m}^{3}$. The thick- ness of the asphalt is $5 \mathrm{~cm}$. According to Articles 3.7 from AASHTO 2002 [24], H20-44 and HS20-44 are considered as live loads. These loads are placed in $3.6 \mathrm{~m}$ traffic lanes. The width of the deck is $9.2 \mathrm{~m}$.

The effect of seismic forces in the longitudinal and transverse directions of the bridge is determined by using the elastic RSA method, where the peak ground acceleration is assumed to be high intensity and the type of soil is II. In this study, the standard design spectrum of Tehran, Iran, (Fig. 1) is used and scaled by considering the importance classification (IC), response modifications factor (R) of bridge, the acceleration coefficient (A) of site, assumed as $\mathrm{A}=0.35, \mathrm{IC}=1$, and $\mathrm{R}=3$ in the longitudinal direction and $\mathrm{R}=5$ in the transverse direction. In determining the axial and shear forces of the columns, coefficient $\mathrm{R}$ must be considered equal to one.

The combination of loads considered for the analysis of bridge is as follows:

$$
\left\{\begin{array}{l}
E Q X C O L=D L+0.5 L L+E Q X+0.3 E Q Y \\
E Q Y C O L=D L+0.5 L L+E Q Y+0.3 E Q X
\end{array},\right.
$$

where $D L$ is dead load, $L L$ is live load, and $E Q$ is earthquake loads which are applied according to RSA method.

\subsection{Design variables}

The variables of beams include compressive strength of concrete $\left(f_{c B}^{\prime}\right)$, depth of cross section $\left(h_{B}\right)$, width of cross section $\left(b_{B}\right)$, number of longitudinal bars $\left(n_{B}\right)$, dimeter of longitudinal bars $\left(d_{b B}\right)$, number of shear bars $\left(n s v_{B}\right)$, space of shear bars $\left(s v_{B}\right)$ and also the variables of columns include, compressive strength of concrete $\left(f_{c C}^{\prime}\right)$, depth of cross section $\left(h_{c}\right)$, width of cross section $\left(b_{c}\right)$, number of longitudinal bars along 3-dir face $\left(n_{c 3}\right)$, number of longitudinal bars along 2-dir face $\left(n_{c 2}\right)$, dimeter of longitudinal bars $\left(d_{b c}\right)$, number of shear bars along 3 -dir face $\left(n s v_{c 3}\right)$,

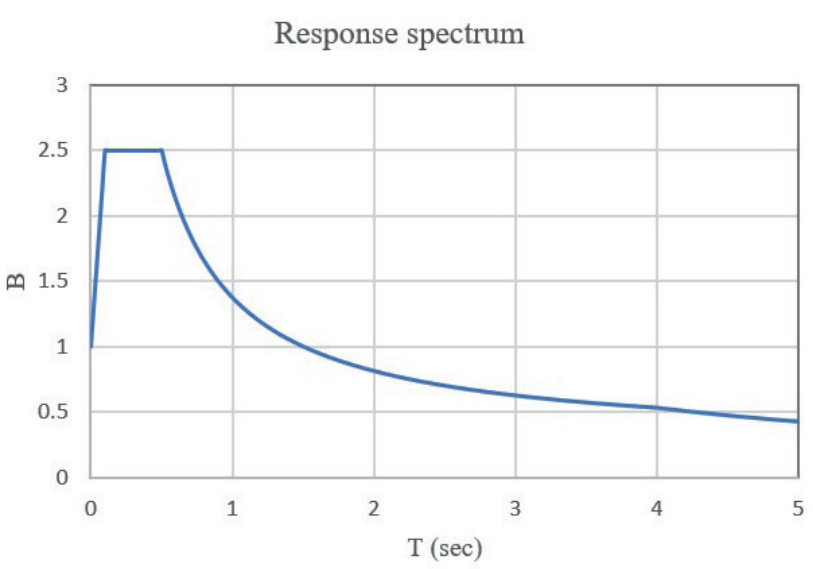

Fig. 1 Standard design spectrum of Tehran 
number of shear bars along 2-dir face $\left(n s v_{c 2}\right)$, space of shear bars $(s v)$, number of shear bars along 3-dir face in plastic region $\left(n s p v_{c 3}\right)$, number of shear bars along 2-dir face in plastic region $\left(n s p v_{c 2}\right)$, space of shear bars in plastic region $\left(s p v_{c}\right)$. The search space of variables is shown in Table 1.

\subsection{Objective functions}

The objective of optimization is economic cost and the $\mathrm{CO}_{2}$ emissions. The general form of both objective functions is presented by Eq. (10), where the unit rate of components varies for the cost and $\mathrm{CO}_{2}$ emission objectives. The unit rates listed in Table 2 [25]. The volume of concrete, the weight of longitudinal and shear reinforcements, and the area of formwork are considered in this problem. $C_{c}, C_{s}$ and $C_{f}$ are the unit rate of concrete, bars and formwork, respectively. $V_{c}$ is the volume of concrete; $\gamma_{s}$ is unit weight of bars that is $7850 \mathrm{~kg} / \mathrm{m}^{3} ; A_{s}$ and $L_{s}$ are the area and length of bars, respectively; $A_{f}$ is area of formwork.

$$
C=\left(V_{c} \cdot C_{c}+C_{s} \cdot \psi_{s} A_{s} \cdot L_{s}+C_{f} \cdot A_{f}\right)
$$

\subsection{Design constraints}

Design variables must be satisfying the limitations and specifications provided by the AASHTO 2002 [24]. By using penalty function, the constrained problem is transformed into an unconstrained problem, and the design variables with penalty are removed from the algorithm in the following iterations.

$$
f_{p}(x)=f \times\left(1+\sum_{i=1}^{n} g_{i}(\boldsymbol{x})\right)^{k}
$$

Table 2 Unit prices and $\mathrm{CO}_{2}$ emissions [25]

\begin{tabular}{lccccc}
\hline \multirow{2}{*}{ Description } & unit & \multicolumn{2}{c}{ Cost $(€)$} & \multicolumn{2}{c}{$\mathrm{CO}_{2}(\mathrm{~kg})$} \\
& & Beam & Column & Beam & Column \\
\hline Steel B-500 & $\mathrm{kg}$ & 1.3 & 1.3 & 3.01 & 3.01 \\
Concrete (25 MPa) & $\mathrm{m}^{3}$ & 78.4 & 77.8 & 132.88 & 132.88 \\
Concrete (30 MPa) & $\mathrm{m}^{3}$ & 82.79 & 82.34 & 143.48 & 143.48 \\
Concrete (35 MPa) & $\mathrm{m}^{3}$ & 98.47 & 98.03 & 143.77 & 143.77 \\
Concrete (40 MPa) & $\mathrm{m}^{3}$ & 105.93 & 105.17 & 143.77 & 143.77 \\
Concrete (45 MPa) & $\mathrm{m}^{3}$ & 112.13 & 111.72 & 143.77 & 143.77 \\
Concrete (50 MPa) & $\mathrm{m}^{3}$ & 118.6 & 118.26 & 143.77 & 143.77 \\
Formwork & $\mathrm{m}^{3}$ & 25.05 & 22.75 & 3.13 & 8.9 \\
\hline
\end{tabular}

Where $f_{p}$ represents the penalized objective function, $f$ denotes the value of the objective function, $x$ indicates the vector of design variables, $g_{i}$ shows the penalty of the $i$ th constraint, $n$ is the number of constraints, and $k$ denotes a penalty exponent, for which $k=1.7$ is considered in this study.

In this study, the units are considered as ton and meter.

\subsubsection{Design constraints for beams}

To design the beams, flexural moments and shear forces are controlled by flexural and shear capacity.

The nominal flexural capacity of a $\mathrm{RC}$ rectangular section of beam, is defined as follows:

$$
\begin{aligned}
& M_{n}=A_{s} f_{y}\left(d-\frac{a}{2}\right), \\
& a=\frac{A_{s} f_{y}}{0.85 f_{c B}^{\prime} b_{B}},
\end{aligned}
$$

\begin{tabular}{|c|c|c|c|c|}
\hline No. & Variable & Symbol & step & Constraints \\
\hline 1 & Concrete strength (ton $/ \mathrm{m}^{2}$ ) & $f_{c}^{\prime}$ & 500 & $2500 \leq f_{c}^{\prime} \leq 5000$ \\
\hline 2 & Yield strength of bars (ton $\left./ \mathrm{m}^{2}\right)$ & $f_{y}$ & constant & 50000 \\
\hline 3 & Width of cross section (m) & $b$ & 0.125 & $0.5 \leq b \leq 2$ \\
\hline 4 & Depth of cross section (m) & $h$ & 0.125 & $0.5 \leq h \leq 2$ \\
\hline 5 & Number of longitudinal bars along 3-dir face & $n_{c 3}$ & 1 & $2 \leq n \leq 17$ \\
\hline 6 & Number of longitudinal bars along 2-dir face & $n_{c 2}$ & 1 & $2 \leq n \leq 17$ \\
\hline 7 & Diameter of longitudinal bars & $d_{b}$ & 1 & $\# 3 \leq d_{b} \leq \# 11$ \\
\hline 8 & Number of shear bars & $n s v$ & 1 & $2 \leq n s v \leq 6$ \\
\hline 9 & Number of shear bars in plastic zone of column & $n s p v$ & 1 & $2 \leq n s p v \leq 6$ \\
\hline 10 & Space of shear bars (m) & $s v$ & 0.05 & $0.05 \leq s v \leq 0.6$ \\
\hline 11 & Space of shear bars in plastic zone of column (m) & $s p v$ & 0.025 & $0.025 \leq s p v \leq 0.125$ \\
\hline 12 & Diameter of shear bars in columns (mm) & $d_{s c}$ & constant & 15 \\
\hline 13 & Diameter of shear bars in beams (mm) & $d_{s b}$ & constant & 12 \\
\hline
\end{tabular}

where $A_{s}$ is the total area of tension reinforcing bars, $f_{v}$ is the yield strength of bars, $d$ is the distance from extreme

Table 1 Design variables and parameters 
compression fiber to the centroid of tension reinforcing bars, and $a$ is the depth of the equivalent rectangular stress block.

The constraint related to the flexural capacity is considered as follows:

$g_{1}=\max \left(0,\left(\frac{\left|M_{u}\right|-\varnothing M_{n}}{\varnothing M_{n}}\right)\right)$,

where $M_{u}$ is the applied ultimate flexural moment, $\varnothing$ is the strength reduction factor which is equal 0.9.

The $\beta_{1}$, stress block factor shall be taken as 0.85 for concrete strengths up to and including $28 \mathrm{MPa}$. For strengths above $28 \mathrm{MPa}, \beta_{1}$ shall be calculated as:

$\beta_{1}=\max \left(0.85-\frac{f_{c}^{\prime}-28}{7} 0.05,0.65\right)$,

The balanced reinforcement ratio $\rho_{b}$ for beams is calculated as follows:

$\rho_{b}=0.85 \beta_{1} \frac{f_{c}^{\prime}}{f_{y}} \frac{60000}{60000+f_{y}}$.

The steel ratio $\rho$ have to be less than 0.75 of the amounts of balanced rebars ratio and must be greater than the minimum rebars ratio.

$\rho=\frac{A_{s}}{b_{B} \cdot d}$

The constraint for limit the maximum reinforcement for the section of beams is:

$g_{2}=\max \left(0,\left(\rho-0.75 * \rho_{b}\right)\right)$.

The minimum distance between bars and minimum reinforcement section of beams are controlled according ACI code [26].

The constraint for limit the minimum reinforcement section of beams is:

$\rho_{\text {min }}=\max \left(\frac{\sqrt{f_{c B}^{\prime}}}{0.4 f_{y}}, \frac{140}{f_{y}}\right), g_{3}=\max \left(0,\left(\rho_{\text {min }}-\rho\right)\right)$.

The constraint for limit the minimum distance between longitudinal bars $\left(S_{l}\right)$ is:

$s_{\text {min }}=\max \left(d_{b B}, 0.025 m\right), g_{4}=\max \left(0,\left(\frac{s_{\text {min }}-S_{l}}{s_{\text {min }}}\right)\right)$.

Where the $d_{b}$ is the diameter of the longitudinal bars.

According to 8.16.6 of AASHTO, the design of crosssection under shear loads shall be as follows:

$V_{u} \leq \phi V_{n}$,
$V_{n}=V_{c}+V_{s}$.

The $V_{c}$ is the nominal shear strength provided by the concrete that is calculated as:

$V_{c}=1.7 * \sqrt{f_{c B}^{\prime}} b_{B} \cdot d($ ton $)$.

The $V_{s}$ is the nominal shear strength provided by the shear reinforcement that is calculated as:

$V_{s}=\frac{A_{V B} f_{y} \cdot d}{s v_{B}}$

In which $A_{V B}$ is the total area the legs of shear rebars. The required $V_{s}$ should not be more than 4 times $V_{c}$.

The constraints related to shear strength are as follows:

$g_{5}=\max \left(0,\left(\frac{\left|V_{u}\right|-\varnothing V_{n}}{\varnothing V_{n}}\right)\right)$.

Where $\varnothing$ is equal to 0.85 and $V_{u}$ is the shear force applied to the cross section.

According to Article 8.19 from AASHTO 2002, the minimum area of the shear bars is:

$A_{V \min }=\frac{35 \cdot b_{B} \cdot s v_{B}}{f_{y}}\left(m^{2}\right)$.

The constraint for limit the minimum shear reinforcement is as follows:

$g_{6}=\max \left(0,\left(\frac{A_{V \min }-\left|A_{V B}\right|}{\left|A_{V B}\right|}\right)\right)$.

The space between the shear rebars $s v_{B}$ should not be greater than the following values.

$$
\begin{aligned}
& S_{\max B} \leq \min \left(\frac{d}{2}, 0.6 m\right) \\
& g_{7}=\max \left(0,\left(s v_{B}-S_{\max B}\right)\right)
\end{aligned}
$$

Where $d$ is the effective height of the cross section of beams.

\subsubsection{Design constraints for columns}

To design the columns, first, the slenderness effects of them are evaluated according to Article 8.16.5.2 from AASHTO. If the column is slenderness, a magnified moment is used in the design of the columns. A column is said to be slenderness when its cross-sectional dimensions are smaller than its length. The slenderness effects $(\lambda)$ are shown by the following equation: 
$\lambda=\frac{K L}{r} \leq 22$,

where $L$ is the unsupported length, $k$ is the effective length coefficient, and $r$ is the radius of gyration. The radius of gyration for the rectangular sections is 0.3 times of the overall dimension in the desired direction. $K$ must be calculated according to Eq. (31). For bending around the transverse axis of the bridge, according to the cantilever behavior, the effective length coefficient will be $k=2$. For bending around the longitudinal axis $(x)$, it is calculated according to the following equations:

$\begin{cases}\psi_{m}<2 & k=\left(1-0.05 \psi_{m}\right) \cdot \sqrt{1+\psi_{m}} \\ \psi_{m}>2 & k=0.2 \cdot \sqrt{1+\psi_{m}}\end{cases}$

$\psi_{m}=\frac{\psi_{t o p}+\psi_{b o t}}{2}$

Parameter $\psi_{t o p}$ indicates the support condition of the end of the compression member. At the beginning of the column, due to the fixed support, $\psi_{b o t}=1$.

$\psi_{\text {top }}=\frac{(E I / L)_{c o l}}{(E I / L)_{c a p}}$

$E=47717 \sqrt{f_{c C}^{\prime}}$

According to 8.16.5.2.5 of AASHTO, if parameter $\lambda$ of the column is greater than 22 , slenderness effects should be considered in the design of the column. The procedure for calculating the coefficient of the magnified moment $\left(\delta_{s}\right)$ is as follows:

$$
\begin{gathered}
\delta_{s}=\frac{1}{1-\frac{\sum N_{u}}{0.65 \cdot \sum P_{c}},} \\
P_{c}=\frac{\pi^{2} \cdot\left(E I_{e}\right)_{c o l}}{(k \cdot L)^{2}},
\end{gathered}
$$

where $\Sigma N_{u}$ is the sum of the axial loads on the column.

The formulation of the magnified moment is as follows:

$$
M c=M c G+\delta_{s} \cdot M c c E,
$$

where $M c$ is magnified moment, $M c G$ is moment under gravitational loads, and $M c c E$ is moment under lateral loads.

According to 8.16.4.2 of AASHTO to check the capacity of the columns, first, the load-moment interaction diagram of the column is drawn for the x-axis. Again, for the y-axis, it is as shown in Fig. 2.

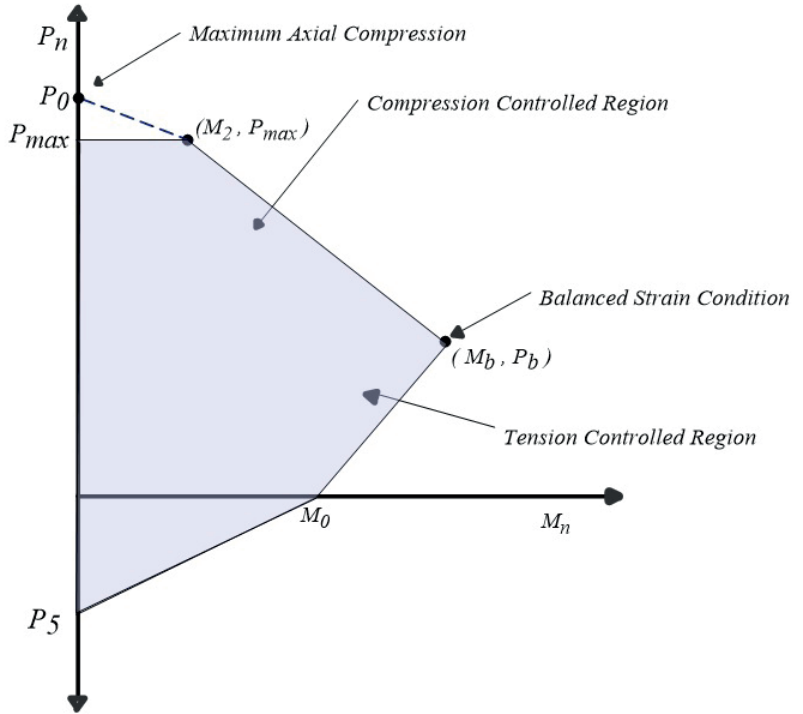

Fig. 2 Column load-moment interaction diagram

Where:

$P_{0}=\varnothing\left[0.85 f_{c C}^{\prime}\left(A_{g}-A_{s t}\right)+A_{s t} \cdot f_{y}\right]$,

$P_{\max }=0.8 * P_{0}$

$P_{b}=\varnothing\left[0.85 f_{c C}^{\prime} \cdot b_{C} \cdot a_{b}+A_{s}^{\prime} \cdot f_{s}^{\prime}-A_{s} \cdot f_{y}\right]$

$M_{b}=\varnothing\left[\begin{array}{l}0.85 f_{c C}^{\prime} \cdot b_{C} \cdot a_{b}\left(d-d^{\prime \prime}-\frac{a_{b}}{2}\right) \\ +A_{s}^{\prime} \cdot f_{s}^{\prime}\left(d-d^{\prime}-d^{\prime \prime}\right)+A_{s} \cdot f_{y} \cdot d^{\prime \prime}\end{array}\right]$,

$a_{b}=\left(\frac{60000}{60000+f_{y}}\right) \cdot \beta_{1} \cdot d$

$f_{s}^{\prime}=\min \left(f_{y},\left[60000 \cdot\left(1-\left(\frac{d^{\prime}}{d}\right) \cdot\left(\frac{60000+f_{y}}{60000}\right)\right)\right]\right.$,

$M_{0}=\varnothing\left[A_{s} \cdot f_{y}\left(d-\frac{a}{2}\right)\right]$

$a=\frac{A_{s} f_{y}}{0.85 f_{c C}^{\prime} b_{C}}$,

The value of $M_{2}$ is calculated as follows:

$M_{2}=M_{b} \cdot\left(\frac{P_{\max }-P_{0}}{P_{b}-P_{0}}\right)$,

$P_{5}=\varnothing \cdot f y \cdot A s t$

In these formulas, the coefficient $\varnothing$ according to Article 7.6.2(B) Division I-A from AASHTO is determined as follows: 
if $\frac{P_{u}}{A_{g}} \geq 0.2 \cdot f_{c C}^{\prime} \quad \varnothing=0.5$,

if $0<\frac{P_{u}}{A_{g}}<0.2 \cdot f_{c C}^{\prime} \quad 0.5<\varnothing<0.9$,

where $A_{g}$ is the total cross-sectional area of the columns, $A_{s t}$ is total area of longitudinal reinforcement, $A_{s}^{\prime}$ is area of compression reinforcement, $A_{s}$ is area of tension reinforcement. The parameters $d, d^{\prime}$ and $d^{\prime \prime}$ are show in Fig. 3 .

The design of columns subjected to biaxial bending should be computed by Eq. (49) or Eq. (52):

$\frac{1}{P_{n x y}}=\frac{1}{P_{n x}}+\frac{1}{P_{n y}}-\frac{1}{P_{0}}$.

And the constrain is:

$g_{8}=\max \left(0,\left(\frac{P_{u}-P_{n x y}}{P_{n x y}}\right)\right)$.

When the factored axial load,

if $P_{u}>0.1 . f_{c C}^{\prime} A_{g}$,

or;

$\frac{M_{u x}}{M_{n x}}+\frac{M_{u y}}{M_{n y}} \leq 1$.

And the constrain is:

$g_{9}=\max \left(0,\left(\frac{M_{u x}}{M_{n x}}+\frac{M_{u y}}{M_{n y}}-1\right)\right)$.

When the factored axial load,

if $P_{u}<0.1 . f_{c C}^{\prime} A_{g}$.

If there is axial uplift force, the constraint is as follows:

$g_{10}=\max \left(0, \frac{P_{u p}-P_{5}}{P_{5}}\right)$.

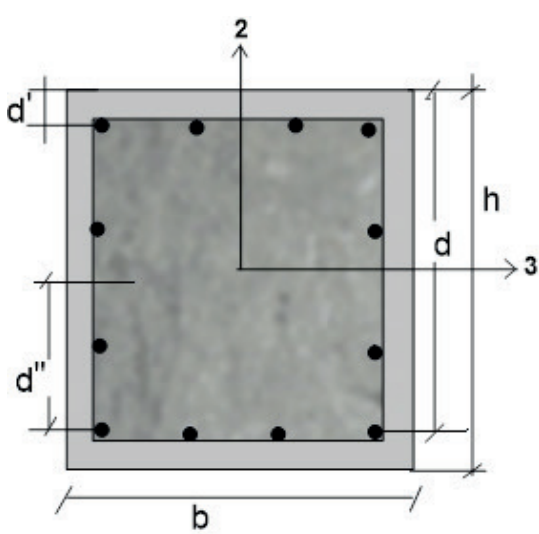

Fig. 3 Specifications of column
Where $P_{u}$ is applied axial load, $P_{n x}$ is nominal axial load strength corresponding to $M_{n x}$ with bending considered in the direction of the $\mathrm{x}$ axis only, $P_{n y}$ is nominal axial load strength corresponding to $M_{n y}$ with bending considered in the direction of the y axis only. $M_{u x}$ is applied ultimate bending moment in the direction of the x axis. $M_{u y}$ is applied ultimate bending moment in the direction of the $y$ axis, $M_{n x}$ is nominal moment strength of a section in the direction of the x axis, $M_{n y}$ is nominal moment strength of a section in the direction of the y axis, $P_{u p}$ is applied axial uplift load.

The penalty function for limitation of minimum and maximum amount longitudinal reinforcement for the columns is expressed as:

$$
\begin{aligned}
& g_{11}=\max \left(0,\left(\frac{0.01 \times A_{g}}{A_{s}}-1\right)\right), \\
& g_{12}=\max \left(0,\left(\frac{A_{s}}{0.06 \times A_{g}}-1\right)\right) .
\end{aligned}
$$

The constraints of the limitation of clear distance between longitudinal bars is defined as:

$s_{\text {min }}=\max \left(1.5 d_{b c}, 0.038 m\right)$,

$g_{13}=\max \left(0,\left(\frac{s_{\text {min }}-s l}{s_{\text {min }}}\right)\right.$,

in which $s l$ is the distance between the longitudinal bars in the columns.

To check the shear strength of the columns, the length of the plastic hinge at the beginning and end of the columns must be determined. Rebars with special specifications should be used in the length of the plastic hinge. The length of the plastic hinge is equal to largest (a) the maximum cross-sectional dimension of the column, (b) onesixth of the clear height of the column, or (c) $450 \mathrm{~mm}$. In this region, the requirement of shear bars is calculated as follows:

The total area of shear reinforcement $\left(A_{s h}\right)$ for a column with rectangular cross-section at plastic hinges shall be either:

$$
A_{s h 1}=0.3 . s p v_{C} \cdot h_{c} \cdot \frac{f_{c C}^{\prime}}{f_{y h}}\left[\frac{A_{g}}{A_{c}}-1\right],
$$

or,

$A_{s h 2}=0.12 \cdot s p v_{C} \cdot h_{c} \cdot \frac{f_{c C}^{\prime}}{f_{y h}}$.

So, 
$A_{s h}=\max \left(A_{s h 1}, A_{s h 2}\right)$,

$g_{14}=\max \left(0,\left(\frac{A_{s h}-A_{s p v}}{A_{s p v}}\right)\right)$,

where $A_{s p v}$ is the total area of the shear reinforcement used in the plastic region, $f_{y h}$ is yield strength of shear reinforcement, and $A_{c}$ is area of column core measured to the outside of the transverse reinforcement.

The shear strength of shear bars in plastic hinge regions is calculated as:

$V_{s p}=\frac{A_{s p v} f_{y h} \cdot d}{s p v_{C}}$,

in which the required $V_{s p}$ should not be more than 4 times of $V_{c}$ and

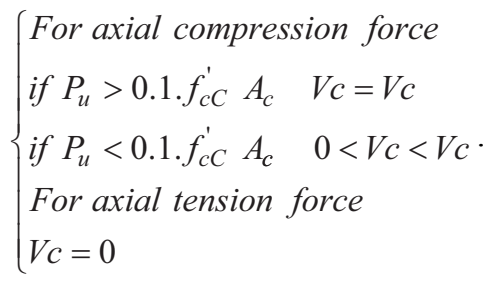

The constraint related to the cross-sectional shear strength is as follows:

$g_{15}=\max \left(0,\left(\frac{\left|V_{u}\right|-\varnothing\left(V_{c}+V_{s p}\right)}{\varnothing\left(V_{c}+V_{s p}\right)}\right)\right)$.

The maximum space of shear reinforcement shall not exceed the smaller of one-quarter of the minimum member dimension or $10 \mathrm{~cm}$.

$$
\begin{aligned}
& s p v_{\text {max }}=\min \left(0.25\left(\min \left(b_{C}, h_{C}\right)\right), 10 c m\right), \\
& g_{16}=\max \left(0,\left(\frac{s p v_{c}-s p v_{\max }}{s p v_{\max }}\right)\right) .
\end{aligned}
$$

In the non-plastic region, the maximum space between the shear bars is as follows:

$$
\begin{aligned}
& s v_{\text {Cmax }}=\min \left(\left(\min \left(b_{c}, h_{c}\right)\right), 30 c m\right), \\
& g_{17}=\max \left(0,\left(\frac{s v_{c}-s v_{C \max }}{s v_{C \max }}\right)\right) .
\end{aligned}
$$

\subsubsection{Geometry constraint}

In the cross section of columns and beams, the width of columns must be smaller than or equal to the depth of section, and the width of column must be smaller than or equal to width of beam.

$$
\begin{aligned}
& g_{18}=\max \left(0,\left(\frac{b_{C}-h_{C}}{h_{C}}\right)\right) \\
& g_{19}=\max \left(0,\left(\frac{b_{C}-b_{B}}{b_{B}}\right)\right)
\end{aligned}
$$

\subsection{Methodology of optimal design}

The link of CSiBridge [27] and MATLAB [28] software are used for the optimization process, where CSiBridge software is used for finite element analysis. The AASHTO 2002 [24] standard specification and optimization algorithm are handled in MATLAB software. The variables of problem are defined in the text file (\$br) of CSiBridge and stored in MATLAB. The information in this document is updated each iteration by optimization algorithm. The CSiBridge can import the information of this file and analyze it. Open Application Programming Interface (OAPI) functions have been used to link of softwares, start CSiBridge application, analysis the 3D model and extract the analysis results to MATLAB.

\section{Numerical example}

A three-span bridge with the length of 15-26-20 m and width of $9.2 \mathrm{~m}$ is considered to study the presented process for the optimal design of 3D reinforced concrete columns and bent caps of the bridges. For this bridge, two symmetrical rectangular columns with one beam are considered in each span (Fig. 4). The optimization is performed with the aim of minimizing the cost and $\mathrm{CO}_{2}$ emissions, and the optimal variables for the columns and beams are obtained using the ECBO optimization algorithm. The design is based on AASHTO 2002 standard specification. The tradeoff between cost and $\mathrm{CO}_{2}$ emissions is also investigated to determine how much $\mathrm{CO}_{2}$ can be reduced if the optimization is based on minimizing $\mathrm{CO}_{2}$ emissions.

Table 3 and Table 4 shows the results of best design for columns and beams of bridge, respectively. In which the objective function is the minimization of the cost. Fig. 5 shows convergence curve of the algorithm corresponding to the lowest cost. The best solution reported is $14638.39 €$,

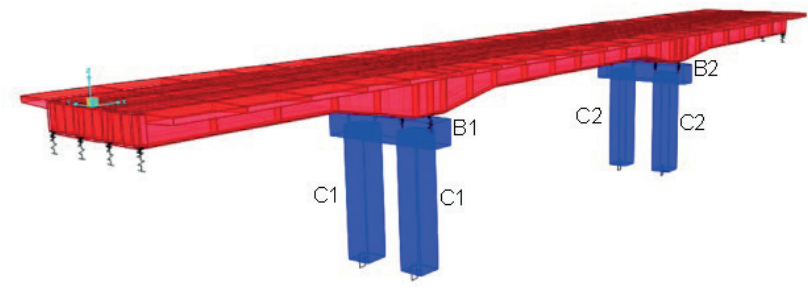

Fig. 4 The RC columns and beams of bridge 
Table 3 Results of the optimum design for cost objective for columns

\begin{tabular}{ccccccccccccccc}
\hline & & $f_{c C}^{\prime}$ & $b_{c}$ & $h_{c}$ & $d_{b c}$ & $n_{C 3}$ & $n_{C 2}$ & $s v_{c}$ & $n s v_{c 3}$ & $n s v_{c 2}$ & $s p v_{c}$ & $n s p v_{c 3}$ & $n s p v_{c 2}$ \\
\hline \multirow{2}{*}{ Column number } & $\mathrm{C} 1$ & 3000 & 1.125 & 1.125 & $\# 8$ & 9 & 6 & 0.3 & 3 & 2 & 0.025 & 2 \\
& $\mathrm{C} 2$ & 3000 & 0.5 & 0.875 & $\# 8$ & 4 & 12 & 0.3 & 2 & 2 & 0.05 & 3 & 2 \\
\hline
\end{tabular}

Table 4 Results of the optimum design for cost objective for beams

\begin{tabular}{|c|c|c|c|c|c|c|c|c|c|c|}
\hline & & $f_{c B}^{\prime}$ & $b_{B}$ & $h_{B}$ & $d_{b B(b o t)}$ & $n_{B(b o t)}$ & $d_{b B(t o p)}$ & $n_{B(t o p)}$ & $n s v_{B}$ & $s v_{B}$ \\
\hline \multirow{2}{*}{ Beam number } & B1 & 3000 & 1.125 & 1.125 & $\# 8$ & 7 & \#8 & 8 & 4 & 0.15 \\
\hline & B2 & 3000 & 0.5 & 0.875 & $\# 6$ & 6 & $\# 8$ & 6 & 4 & 0.15 \\
\hline
\end{tabular}

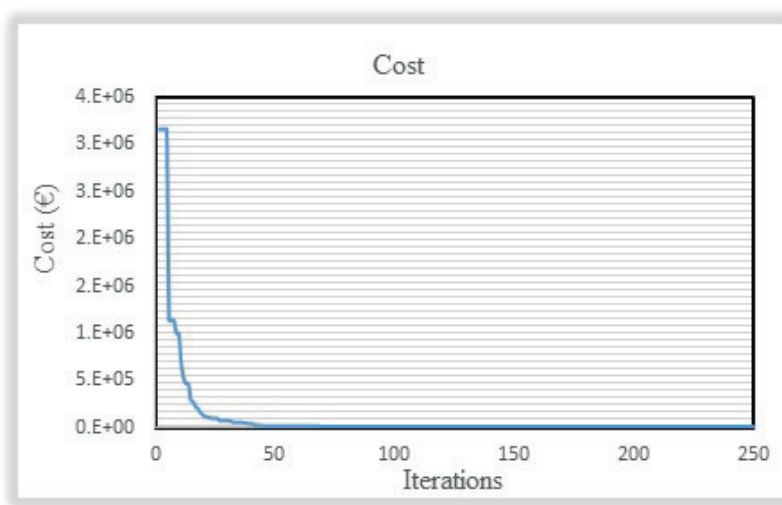

Fig. 5 Convergence curve of the algorithm corresponding to the lowest cost

with $26274.4 \mathrm{~kg}$ of $\mathrm{CO}_{2}$ emissions. In the solution with the cost objective, based on the examinations, the suitable value for the parameter Pro of algorithm is 0.4 and the number of population is 30 . The $C M$ size and stopping criteria of the algorithm are considered as $20 \%$ of the population size and 250 iterations, respectively.

The optimization results with the aim of minimizing the $\mathrm{CO}_{2}$ emissions are given in Table 5 and Table 6 for the columns and beams, respectively. The best reported solution is $24667.6 \mathrm{~kg} \mathrm{CO}$ emissions with $14844.5 €$ of cost. Convergence curve of the algorithm corresponding to the lowest $\mathrm{CO}_{2}$ is show in Fig. 6. In the solution with the $\mathrm{CO}_{2}$ objective, based on the examinations, the suitable value for the parameter Pro of the algorithm is 0.8 , and the

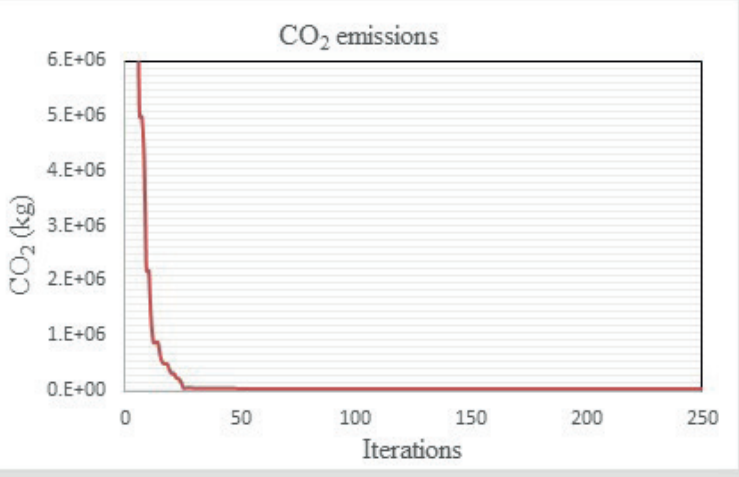

Fig. 6 Convergence curve of the algorithm corresponding to the lowest

$$
\mathrm{CO}_{2} \text { emissions }
$$

number of population is 30 . The $C M$ size and stopping criteria of algorithm are considered as $20 \%$ of the population size and 250 iterations, respectively.

A percentage comparison of the results with the aim of minimizing the cost and $\mathrm{CO}_{2}$ emissions shows that in design with the objective functions of minimizing $\mathrm{CO}_{2}$ compared to the design based on cost minimization, with a $1.4 \%$ increase in cost, $\mathrm{CO}_{2}$ can be reduced by $6.1 \%$

\section{Conclusions}

Construction industry has a significant contribution to $\mathrm{CO}_{2}$ emissions. Researchers have employed a number of strategies to reduce the $\mathrm{CO}_{2}$ emissions from the $\mathrm{RC}$ structure, one of which is the use of optimization techniques during

Table 5 Results of the optimum design for $\mathrm{CO} 2$ objective for columns

\begin{tabular}{cccccccccccccc}
\hline & & $f_{c C}^{\prime}$ & $b_{c}$ & $h_{c}$ & $d_{b c}$ & $n_{C 3}$ & $n_{C 2}$ & $s v_{c}$ & $n s v_{c 3}$ & $n s v_{c 2}$ & $s p v_{c}$ & $n s p v_{c 3}$ & $n s p v_{c 2}$ \\
\hline \multirow{2}{*}{ Column number } & $\mathrm{C} 1$ & 3500 & 0.875 & 1.125 & $\# 6$ & 5 & 16 & 0.3 & 3 & 2 & 0.1 & 5 \\
& $\mathrm{C} 2$ & 3500 & 0.875 & 1.125 & $\# 6$ & 3 & 17 & 0.3 & 2 & 2 & 0.075 & 4 & 3 \\
\hline
\end{tabular}

Table 6 Results of the optimum design for $\mathrm{CO} 2$ objective for beams

\begin{tabular}{|c|c|c|c|c|c|c|c|c|c|c|}
\hline & & $f_{c B}^{\prime}$ & $b_{B}$ & $h_{B}$ & $d_{b B(b o t)}$ & $n_{B(b o t)}$ & $d_{b B(t o p)}$ & $n_{B(t o p)}$ & $n s v_{B}$ & $s v_{B}$ \\
\hline \multirow{2}{*}{ Beam number } & $\mathrm{B} 1$ & 3000 & 0.875 & 2 & $\# 10$ & 7 & $\# 7$ & 14 & 3 & 0.35 \\
\hline & B2 & 3000 & 0.875 & 1 & $\# 5$ & 12 & $\# 7$ & 9 & 3 & 0.1 \\
\hline
\end{tabular}


the design phase. Studies have been conducted to reduce $\mathrm{CO}_{2}$ emissions on superstructures of bridges, but the tradeoff between cost and $\mathrm{CO}_{2}$ emission in the columns and bent caps (beams) has not been investigated. This study describes a methodology for the optimal design of 3D reinforced concrete columns and beams of bridge. The objective function is to minimize the cost or the $\mathrm{CO}_{2}$ emissions. A computer tool with the link of CSiBridge and Matlab software is used for the optimal design of 3D structures. CSiBridge software is employed for finite element analysis, and the AASHTO standard specification and optimization algorithms are handled in MATLAB software. The

\section{References}

[1] Martí, J. V., Gonzalez-Vidosa, F., Yepes, V., Alcalá, J. "Design of prestressed concrete precast road bridges with hybrid simulated annealing", Engineering Structures, 48, pp. 342-352, 2013. https://doi.org/10.1016/j.engstruct.2012.09.014

[2] Srinivas, V., Ramanjaneyulu, K. "An integrated approach for optimum design of bridge decks using genetic algorithms and artificial neural networks", Advances in Engineering Software, 38(7), pp. 475-487, 2007.

https://doi.org/10.1016/j.advengsoft.2006.09.016

[3] Kaveh, A., Maniat, M., Arab Naeini, M. "Cost optimum design of post-tensioned concrete bridges using a modified colliding bodies optimization algorithm", Advances in Engineering Software, 98, pp. 12-22, 2016.

https://doi.org/10.1016/j.advengsoft.2016.03.003

[4] Pedro, R. L., Demarche, J., Miguel, L. F. F., Lopez, R. H. "An efficient approach for the optimization of simply supported steel-concrete composite I-girder bridges", Advances in Engineering Software, 112, pp. 31-45, 2017.

https://doi.org/10.1016/j.advengsoft.2017.06.009

[5] Yepes, V., Pérez-López, E., García-segura, T., Alcalá, J. "Optimization of High-Performance Concrete Post-Tensioned BoxGirder Pedestrian Bridge", International Journal of Computational Methods and Experimental Measurements, 7(2), pp. 118-129, 2019. https://doi.org/10.2495/CMEM-V7-N2-118-129

[6] Penadés-Plà, V., García-Segura, T., Yepes, V. "Robust Design Optimization for Low-Cost Concrete Box-Girder Bridge", Mathematics, 8(3), Article numbers: 398, 2020. https://doi.org/10.3390/math8030398

[7] Mergos, P. E. "Seismic design of reinforced concrete frames for minimum embodied $\mathrm{CO}_{2}$ emissions", Energy and Buildings, 162, pp. 177-186, 2018.

https://doi.org/10.1016/j.enbuild.2017.12.039

[8] Park, H. S., Hwang, J. W., Oh, B. K. "Integrated analysis model for assessing $\mathrm{CO}_{2}$ emissions, seismic performance, and costs of buildings through performance-based optimal seismic design with sustainability", Energy and Buildings, 158, pp. 761-775, 2018. https://doi.org/10.1016/j.enbuild.2017.10.070 best combination of design variables, including geometry, compressive strength of concrete, as well as longitudinal and shear reinforcement is obtained with the ECBO optimization algorithm. A comparison between designs with the objective of minimizing cost and minimizing $\mathrm{CO}_{2}$ emissions indicates that in designs considering the minimization of $\mathrm{CO}_{2}$ emissions, this case can be decreased by $6.1 \%$ with a relatively small increase in the cost.

\section{Compliance with ethical standards}

Conflict of interest: No potential conflict of interest was reported by the authors.

[9] Kaveh, A., Mottaghi, L., Izadifard, R. A. "Sustainable design of reinforced concrete frames with non-prismatic beams", Engineering with Computers, 2020.

https://doi.org/10.1007/s00366-020-01045-4

[10] Mottaghi, L., Izadifard, R. A., Kaveh, A. "Factors in the Relationship Between Optimal CO2 Emission and Optimal Cost of the RC Frames", Periodica Polytechnica Civil Engineering, 65(1), pp. 1-14, 2021.

https://doi.org/10.3311/PPci.16790

[11] Kaveh, A., Izadifard, R. A., Mottaghi, L. "Optimal design of planar RC frames considering $\mathrm{CO}_{2}$ emissions using ECBO, EVPS and PSO metaheuristic algorithms", Journal of Building Engineering, 28, Article numbers: 101014, 2020.

https://doi.org/10.1016/j.jobe.2019.101014

[12] Camp, C. V., Assadollahi, A. " $\mathrm{CO}_{2}$ and cost optimization of reinforced concrete footings subjected to uniaxial uplift", Journal of Building Engineering, 3, pp. 171-183, 2015. https://doi.org/10.1016/j.jobe.2015.07.008

[13] Yepes, V., Martí, J. V., García-Segura, T. "Cost and $\mathrm{CO}_{2}$ emission optimization of precast-prestressed concrete U-beam road bridges by a hybrid glowworm swarm algorithm", Automation in Construction, 49(A), pp. 123-134, 2015.

https://doi.org/10.1016/j.autcon.2014.10.013

[14] García-Segura, T., Yepes, V., Alcalá, J., Pérez-López, E. "Hybrid harmony search for sustainable design of post-tensioned concrete box-girder pedestrian bridges", Engineering Structures, 92, pp. 112$122,2015$.

https://doi.org/10.1016/j.engstruct.2015.03.015

[15] García-Segura, T., Yepes, V. "Multiobjective optimization of posttensioned concrete box-girder road bridges considering cost, $\mathrm{CO}_{2}$ emissions, and safety", Engineering Structures, 125, pp. 325-336, 2016.

https://doi.org/10.1016/j.engstruct.2016.07.012

[16] Martínez, F. J., González-Vidosa, F., Hospitaler, A., Yepes, V. "Heuristic optimization of RC bridge piers with rectangular hollow sections", Computers and Structures, 88 (5-6), pp. 375-386, 2010. https://doi.org/10.1016/j.compstruc.2009.11.009 
[17] Martínez, F. J., González-Vidosa, F., Hospitaler, A., Alcalá, J. "Design of tall bridge piers by ant colony optimization", Engineering Structures, 33(8), pp. 2320-2329, 2011. https://doi.org/10.1016/j.engstruct.2011.04.005

[18] Fazli, H., Pakbaz, A. "Performance-Based Seismic Design Optimization for Muli-Column RC Bridge Piers, Considering Quasi-Isolation", International Journal of Optimization in Civil Engineering, 8(4), pp. 525-545, 2018.

[19] Kaveh, A., Mahdavi, V. R. "Colliding bodies optimization: A novel meta-heuristic method", Computers and Structures, 139, pp. 18-27, 2014.

https://doi.org/10.1016/j.compstruc.2014.04.005

[20] Kaveh, A., Ilchi Ghazaan, M. "Enhanced colliding bodies optimization for design problems with continuous and discrete variables", Advances in Engineering Software, 77, pp. 66-75, 2014. https://doi.org/10.1016/j.advengsoft.2014.08.003

[21] Kaveh, A., Mottaghi, L., Izadifard, R. A. "An integrated method for sustainable performance-based optimal seismic design of RC frames with non-prismatic beams", Scientia Iranica, 28(5), pp. 2596-2612, 2021.

https://doi.org/10.24200/SCI.2021.58452.5728
[22] Kaveh, A. "Advances in metaheuristic algorithms for optimal design of structures", 3rd ed., Springer, Cham, Switzerland, 2021. https://doi.org/10.1007/978-3-030-59392-6

[23] Kaveh, A., Ilchi Ghazaan, M. "Meta-heuristic algorithms for optimal design of real-size structures", Springer, Cham, Switzerland, 2018. https://doi.org/10.1007/978-3-319-78780-0

[24] AASHTO "Standard Specifications for Highway Bridges", American Association of State Highway and Transportation Officials, Washington, DC, USA, 2002.

[25] Camp, C.V., Huq, F. " $\mathrm{CO}_{2}$ and cost optimization of reinforced concrete frames using a big bang-big crunch algorithm", Engineering Structures, 48(2), pp. 363-372, 2013. https://doi.org/10.1016/j.engstruct.2012.09.004

[26] ACI Committee 318 "ACI 318-08 Building Code Requirements for Structural Concrete (ACI 318-08) and Commentary", American Concrete Institute, Farmington Hills, MI, USA, 2008.

[27] CSI Computers and Structures, Inc. "CSiBridge ${ }^{\circledR}$ Bridge Analysis, Desingn and Rating" [online] Available at: https://www.csiamerica. com/products/csibridge

[28] MathWorks "MATLAB ${ }^{\circledR "}$ [online] Available at: https://www.mathworks.com/products/matlab.html 